\title{
Performansi Mesin Pendingin Tipe Chiller untuk Cold Storage dan Indoor Menggunakan Ethylene Glycol Coolant
}

\author{
Azridjal Aziz ${ }^{1}$, Hendrik Syahputra ${ }^{1}$,Rahmat Iman Mainil ${ }^{1}$, Afdhal Kurniawan $\mathbf{M}^{2}$ \\ ${ }^{1}$ Laboratorium Rekayasa Termal, Jurusan Teknik Mesin, Fakultas Teknik, Universitas Riau \\ Kampus Bina Widya Km 12,5 Simpang Baru Panam, Pekanbaru 28293 \\ ${ }^{2}$ Jurusan Teknik Mesin, Fakultas Teknik, Universitas Bengkulu \\ Jl. WR Supratman Kandang Limun, Bengkulu 38371A \\ E-mail: azridjal@yahoo.com, hendriksyahputra10121991@gmail.com,rahmat.iman@gmail.com, \\ afdhal_km@yahoo.com
}

\begin{abstract}
Refrigeration device is used to reduce the temperature of the room or cooled material by absorbing heat from the room/material. The most refrigeration device operated by using the vapor compression refrigeration cycle. This research was done experimentally using refrigeration device chiller type to cool the ethylene glycol coolant in the refrigeration box (evaporator unit), and ethylene glycol coolant is used to absorb heat in cold storage and indoor (test room). The results show for the circulation of ethylene glycol coolant to the cold storage COP value is 2.80, while the circulation of ethylene glycol coolant to the indoor COP value is 5.12. On the testing of ethylene glycol coolant was circulated to the indoor with 1000 Watt cooling load, the COP value is 5.19, and for circulated to the cold storage and indoor simultaneously COP is of 3.66. The performance of chiller refrigeration device is influenced by the cooling load, the greater of cooling load that would affect the work of the compressor so that the pressure in compressor increase and the energy consumption to operate the compressor also increasing too.
\end{abstract}

Keywords: refrigeration, heat, COP, PF, cooling load.

\section{PENDAHULUAN}

Refrigerasi atau pendinginan adalah proses penyerapan/pemindahan/pengambilan kalor dari media atau ruangan yang akan didinginkan. Kalor yang dipindahkan dari makanan akan menjaga kualitas dan rasa sehingga dapat digunakan untuk jangka waktu yang lebih lama. Kalor yang dipindahkan dari ruangan akan memberikan kenyamanan bagi orang yang ada dalam ruangan tersebut. Aplikasi refrigerasi sangat banyak penerapannya baik untuk rumah tangga, perkantoran, pusat perbelanjaan, pusat perdagangan, dan industri, dimana kalor dipindahkan dari ruangan atau bahan untuk mencapai efek pendinginan yang diinginkan. Sebagian besar aplikasi refrigerasi dioperasikan menggunakan mesin refrigerasi siklus kompresi uap (SKU) [1].

Kebanyakan makanan yang disimpan pada temperatur ruang atau lingkungan akan cepat basi. Untuk Indonesia yang terletak di daerah tropis temperatur ruang atau lingkungan rata-rata $28^{\circ} \mathrm{C}$ $34^{\circ} \mathrm{C}$ pada siang hari dan sekitar $21^{\circ} \mathrm{C}-25^{\circ} \mathrm{C}$ pada malam hari di musim kemarau. Sedangkan pada musim penghujan temperatur rata-rata lebih dingin, sekitar $24^{\circ} \mathrm{C}-28^{\circ} \mathrm{C}$ pada siang hari dan pada malam hari temperatur rata-rata sedikit lebih hangat dibanding musim Kemarau, yaitu sekitar $23^{\circ} \mathrm{C}-26^{\circ} \mathrm{C}$ [2]. Makanan yang dibiarkan pada temperatur ruang, bakteri pada makanan akan cepat tumbuh dan berkembang, sehingga makanan akan cepat membusuk atau basi. Hal ini disebabkan pertumbuhan yang cepat dari bakteri pada temperatur ruang. Pada temperatur refrigerasi sekitar $40^{\circ} \mathrm{F}$ $\left(4,4^{\circ} \mathrm{C}\right)$, bakteri tumbuh sangat lambat, sehingga makanan pada temperatur ini dapat disimpan lebih lama. Refrigerasi dapat mempertahankan kesegaranan makanan dengan menjaganya agar tetap dingin [3].

Pengawetan makanan dapat dilakukan dengan cara mendinginkannnya. Mesin pendingin umumnya digunakan sebagai penyejuk ruangan (AC), mendinginkan minuman (beverage cooling), membekukan makanan/minuman, membuat es krim dan lain-lain. Mesin pendingin juga digunakan pada berbagai jenis kendaraan seperti mobil, bus, kereta api, kapal laut, pesawat terbang untuk kenyamanan berkendara. Untuk penggunaan di rumah tangga digunakan lemari es dapat menyimpan susu, sayuran, buah-buahan, daging dan lain-lain. Untuk mendistribusikan makanan/minuman agar tidak rusak, mesin pendingin digunakan pada mobil/truk pengangkut daging, sayuran, ikan, buah-buahan agar awet dan tetap segar sampai di tempat tujuan [4]. 
Penelitian yang dilakukan tentang performansi mesin pendingin telah banyak dilakukan. Negara dkk [5], telah melakukan penelitian tentang analisa performansi sistem pendingin ruangan dan efisiensi energi listrik pada sistem water chiller dengan penerapan metode cooled energy storage. Penelitian tersebut menunjukkan bahwa nilai performansi sistem pendingin dengan penggunaan full sistem lebih rendah dari pada performansi sistem pendingin pada penggunaan half sistem. Hal ini dapat dilihat pada hasil perhitungan kerja kompresi, dampak refrigerasi dan COP. Performansi mesin refrigerasi kompresi uap ditentukan oleh beberapa parameter, diantaranya adalah kapasitas pendingin, kapasitas pemanasan, daya kompresi, koefisien performansi dan performansi faktor [6].

Yudisworo dkk [7] juga telah melakukan penelitian tentang cooling unit performance analysis of fish (cold storage) to Improve quality in fishermen catch cirebon. Dari penelitian tersebut didapat nilai COP aktual yang dicapai oleh cold storage tersebut adalah sekitar 2,24 lebih kecil dari COP carnot nya yang sebesar 4,13.

Wahyudi dan Ulud [8], telah melakukan rancang bangun mesin pendingin bertemperatur dibawah $0^{\circ} \mathrm{C}$ untuk Cold Storage System. Pengujian dilakukan selama 750 menit $(12,5)$ jam dengan hasil koofisien perpindahan panas total $\left(\mathrm{U}_{\mathrm{o}}\right) \quad 85,703$ $\mathrm{W} / \mathrm{m}^{2} \mathrm{~K}$, luas permukaan perpindahan panas $\left(\mathrm{A}_{\mathrm{o}}\right)$ $0,153 \mathrm{~m}^{2}$, dan panjang total pipa evaporator $\left(\mathrm{L}_{\mathrm{tot}}\right)$ $4,88 \mathrm{~m}$, temperatur cairan khusus $-4,59^{\circ} \mathrm{C}$, temperatur ruangan evaporator $-3,87^{\circ} \mathrm{C}$, temperatur cold storage$0,53^{\circ} \mathrm{C}$, temperatur indoor $25,03^{\circ} \mathrm{C}$.

Penelitian ini merupakan penelitian lanjutan, menggunakan alat uji yang sama hasil rancang bangun Wahyudi dan Ulud [8]. Penelitian ini bertujuan untuk mengetahui performansi mesin pendingin bertemperatur dibawah $0^{\circ} \mathrm{C}$ untuk Cold Storage System. Pada pengujian ini ethylene glycol coolant dari box refrigerasi disirkulasikan ke cold storage, dan juga disirkulasikan ke ruangan (indoor). Studi juga dilakukan terhadap pengaruh beban pendingin terhadap performansi mesin pendingin tipe chiller untuk cold storage dan indoor menggunakan ethylene glycol coolant serta perbedaan temperatur ethylene glycol coolant yang disirkulasikan ke cold storage dan indoor.

\section{METODOLOGI}

Penelitian ini dilakukan secara eksperimental menggunakan sebuah mesin pendingin tipe chiller dengan daya kompresor 120 Watt, dengan fluida kerja R134a. Skematik diagram mesin pendingin tipe chiller ini ditunjukkan pada Gambar 1 [9].
Evaporator ditempatkan dalam box refrigerasi yang akan mendinginkan ethylene glycol coolant. Ethylene glycol coolant ini kemudian dipompakan ke cold storage untuk penyimpanan dingin dan ke ruangan uji (indoor) dengan mengatur katup seperti tampak pada Gambar 1. Pengujian ini menggunakan 1 unit alat mesin pendingin tipe chiller untuk cold storage dan indoor dengan fluida kerja R134a, dengan memanfaatkan evaporator dari box refrigerasi sebagai sumber pendinginnya, dimana evaporator dipasang selang menuju cold storage sebagai penyimpanan dingin, dan dari box refrigerasi tersebut juga disalurkan menuju indoor (ruangan) menggunakan selang yang diatur dengan katup.

Ethylene glycole merupakan senyawa turunan ethylena yang termasuk golongan poly alkohol. Ethylene glycole mudah larut dalam air dan mempunyai titik beku yang cukup rendah yaitu pada $-11,5^{\circ} \mathrm{C}$. Air membeku pada temperatur $0^{\circ} \mathrm{C}$. Namun, dengan menambahkan ethylene glycole kedalamnya, titik beku air akan turun, sehingga Pada merek dagang radiator coolant, prestone, yang berisi water, ethylene glycole, diethylene glycole, Sodium ethyle hexanoate dan sodium neodecanoate, diperoleh titik beku hingga $-37^{\circ} \mathrm{C}$ [10]. Hal ini sesuai dengan sifat koligatif larutan, bahwa penambahan zat terlarut kedalam air murni (zat pelarut) akan menurunkan titik beku air tersebut. Dalam hal ini, penggunaan ethylene glycole sebagai refrigeran sekunder media penyerapan kalor di evaporator dapat menurunkan titik beku air. Ikatan hydrogen antara molekul ethylene glycole dan molekul air sangat berperan dalam menurunkan titik beku. Molekul ethylene glycole akan menghalangi pembekuan molekul air, sehingga air yeng ditambahkan ethylene glycole akan sukar membeku atau membeku jauh di bawah titik beku air [11].

Proses pengambilan data dilakukan seperti tampak pada Gambar 2 tentang diagram alir pengambilan data. Pengujian dilakukan dalam empat cara pengoperasian dan kemudian hasilnya dibandingkan untuk melihat mode pengoperasian yang memberikan performansi terbaik. Pada pengoperasian pertama sistem siklus mesin pendingin tipe chiller cairan ethylene glycol coolant disalurkan ke cold storage, kemudian pengoperasian kedua disalurkan ke indoor, lalu pengoperasian ketiga disalurkan ke indoor dengan beban 1000 Watt, terakhir pengoperasian keempat disalurkan full system ke cold storage dan indoor secara bersamaan. Waktu yang dibutuhkan untuk mendinginkan ethylene glycol coolant adalah selama 4 jam sebelum disirkulasikan ke cold storage atau indoor. Pengamatan terhadap temperatur dan tekanan sistem dilakukan setiap 10 menit selama 2 jam (120 menit). 
Temperatur sistem diukur mengggunakan data logger omega TC-08 dengan $\mathrm{K}$ termokopel tipe (ketelitian 0,2 persen $\pm 0.5^{\circ} \mathrm{C}$ dan memiliki resolusi $\left.0.1^{\circ} \mathrm{C}\right)$. Kecermatan termometer digital adalah \pm $0,1^{\circ} \mathrm{C}$. Tekanan sistem diukur menggunakan alat pengukur tekanan tipe bourdon dengan akurasi \pm 5 psi (refrigeran tekanan tinggi di sisi kondensor) dan \pm 1 psi (refrigeran tekanan rendah di sisi evaporator). Arus dan tegangan listrik kompresor diukur menggunakan amperemeter (ketelitian $\pm 2,0$ persen) dan voltmeter (ketelitian $\pm 1,0$ persen).

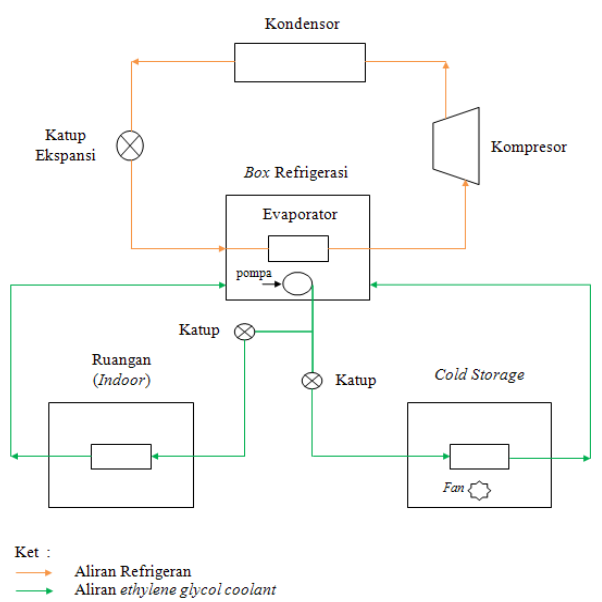

Gambar 1. Siklus mesin pendingin tipe chiller untuk cold storage dan indoor [9]
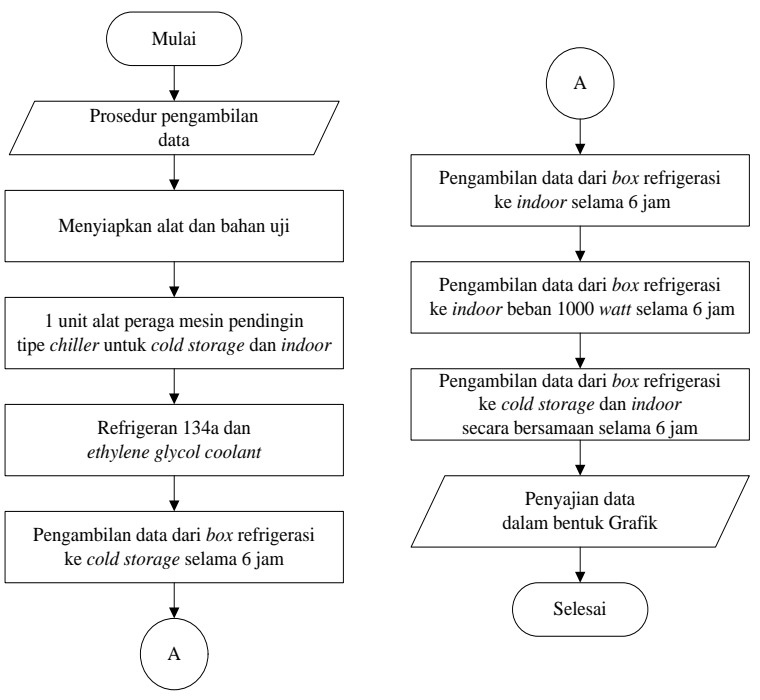

Gambar 2. Diagram alir pengambilan Data

Analisis termodinamika siklus kompresi uap pada kondisi ideal dihitung dari diagram P-h seperti tampak pada Gambar 3 [12]. Analisis termodinamika yang dilakukan mencakup kerja kompresi, laju aliran massa refrigeran, kapasitas kalor buang di kondensor, kapasitas penyerapan kalor/pendinginan di evaporator, koefisien kinerja coefficient of performance (COP), faktor prestasi/performance factor (PF) [12].

Kerja kompesor pada kondisi isentropik $\left(W_{i n}\right)$ dinyatakan dalam persamaan 1 :

$$
W_{\text {in }}=\dot{m}\left(h_{2}-h_{1}\right)
$$

dimana $\dot{m}$ adalah laju aliran massa refrigeran $(\mathrm{kg} / \mathrm{s})$, $h_{1}$ dan $h_{2}$ adalah entalpi spesifik masuk dan keluar kompresor $(\mathrm{kJ} / \mathrm{kg})$. Kerja kompresor juga dapat dihitung dari daya listrik yang dibutuhkan untuk menggerakkan kompresor seperti dinyatakan dalam persamaan 2:

$$
W_{\text {in }}=V I \cos \phi
$$

dimana $V$ dan $I$ adalah tegangan dan arus listrik yang masuk ke kompresor.
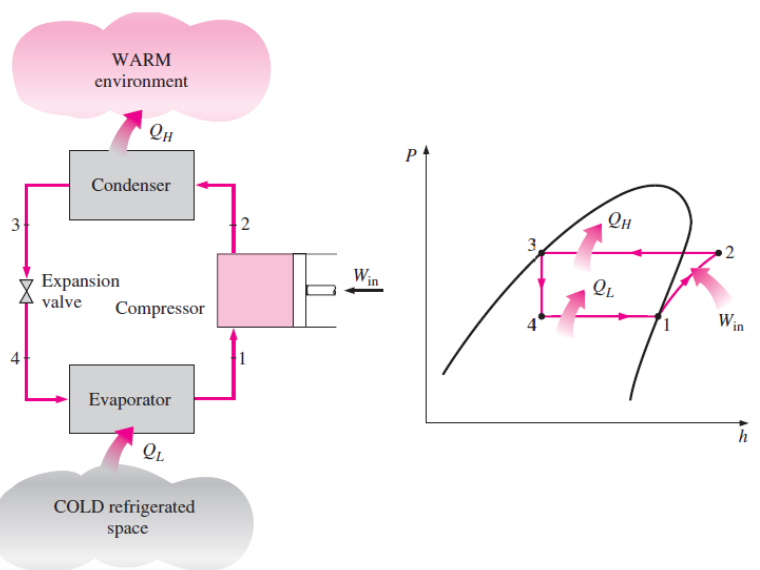

Gambar 3. Skematik dan P-h diagram siklus kompresi uap ideal [12]

Kapasitas kalor buang di kondensor $\left(Q_{H}\right)$ dianalisis menggunakan persamaan 3:

$$
Q_{H}=\dot{m}\left(h_{2}-h_{3}\right)
$$

dimana $h_{3}$ adalah entalpi spesifik keluar kondensor $(\mathrm{kJ} / \mathrm{kg})$.

Kapasitas penyerapan kalor/pendinginan di evaporator $\left(Q_{L}\right)$ dihitung menggunakan persamaan 4 :

$$
Q_{L}=\dot{m}\left(h_{1}-h_{4}\right)
$$

dimana $h_{4}$ adalah entalpi spesifik masuk ke evaporator $(\mathrm{kJ} / \mathrm{kg})$. 
Koefisien kinerja mesin refrigerasi atau coefficient of performance (COP) merupakan kapasitas penyerapan kalor atau pendinginan di evaporator terhadap kerja kompresor seperti dinyatakan dalam persamaan 5:

$$
C O P=Q_{L} / W_{\text {in }}
$$

Faktor prestasi mesin refrigerasi atau performance factor (PF) merupakan kapasitas kalor buang di kondensor terhadap kerja kompresor dihitung menggunakan persamaan 6 :

$$
P F=Q_{H} / W_{\text {in }}
$$

Proses pengambilan data dilakukan setelah ethylene glycol coolant di box refrigerasi didinginkan terlebih dahulu oleh refrigeran pada siklus mesin pendingin kompresi uap selama 4 jam. Setelah mencapai titik pendinginan ethylene glycol coolant, kemudian ethylene glycol coolant disirkulasikan ke cold storage dan indoor dan dilakukan pengambilan data selama 2 jam.

\section{HASIL DAN PEMBAHASAN}

Analisis termodinamika terhadap kinerja mesin pendingin tipe chiller dihitung berdasarkan siklus kompresi uap ideal menggunakan persamaan 1 sampai persamaan 6. Analisis kinerja mesin pendingin yang dibahas meliputi kerja kompresi, kapasitas pembuangan kalor di kondensor, kapasitas penyerapan kalor di evaporator, laju pendinginan, temperatur, koefisien performansi/COP dan faktor prestasi/PF.

Gambar 4 menunjukkan kerja kompresi mesin pendingin tipe chiller pada pengoperasian selama 2 jam. Dari Gambar 4 terlihat bahwa perbandingan kerja kompresi terhadap waktu mengalami peningkatan, hasil pengujian kerja kompresi rata-rata pada cold storage adalah $0,096 \mathrm{~kW}$, pengujian pada indoor kerja kompresi rata-ratanya adalah 0,1021 $\mathrm{kW}$. Sedangkan pengujian pada indoor dengan beban 1000 Watt kerja kompresi rata-ratanya $0,1028 \mathrm{~kW}$, dan pada cold storage dan indoor yang dioperasikan secara bersamaan kerja kompresi rata-ratanya adalah $0,1688 \mathrm{~kW}$. Nilai tertinggi diperoleh pada pengujian ke cold storage dan indoor secara bersamaan, dan nilai terendah diperoleh pada pengujian ke cold storag. Hal ini dikarenakan kerja kompresi sangat dipengaruhi oleh arus listrik, semakin besar arus listrik yang diserap kompresor maka semakin besar pula kerja kompresi yang diberikan, begitu juga sebaliknya semakin kecil arus yang diserap kompresor maka kerja kompresi akan semakin kecil.

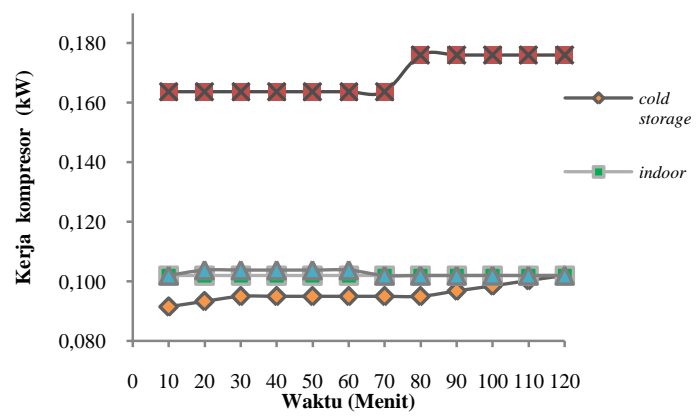

Gambar 4. Grafik perbandingan kerja kompresi terhadap waktu

Gambar 5 menunjukkan kapasitas kalor buang kondensor mesin pendingin tipe chiller pada pengoperasian selama 2 jam. Dari Gambar 5 tampak bahwa kapasitas kalor buang kondensor dari masingmasing pengujian tampak berbeda, kapasitas kalor buang kondensor rata-rata pada cold storage yaitu $0,286 \mathrm{~kW}$, pada indoor sebesar 0,4728 kW. Kapasitas kalor buang kondensor rata-rata pada indoor dengan beban 1000 Watt adalah sebesar $0,6139 \mathrm{~kW}$, dan pada cold storage dan indoor secara bersamaan kapasitas kalor buang kondensor rata-ratanya sebesar $0,8015 \mathrm{~kW}$.

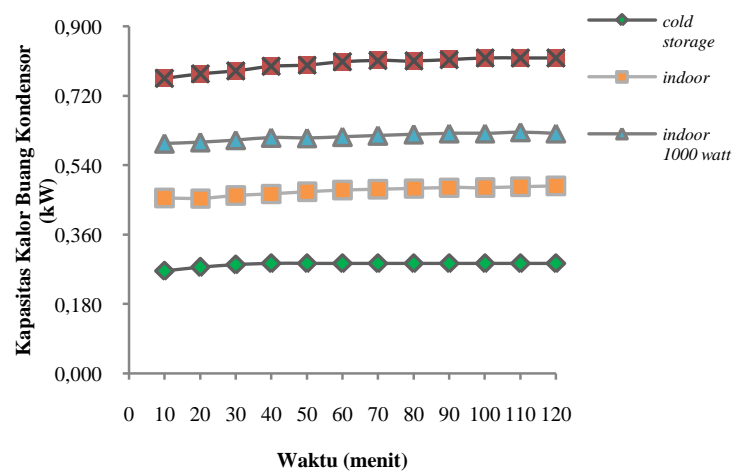

Gambar 5. Grafik perbandingan kapasitas kalor buang kondensor terhadap waktu

Nilai rata-rata kapasitas kalor buang kondensor terbesar diperoleh pada pengujian ke cold storage dan indoor secara bersamaan, dan nilai rata-rata terkecil diperoleh pada pengujian disirkulasikan ke cold storage. Perbedaan ini diakibatkan karena kapasitas kalor buang kondensor dipengaruhi oleh laju aliran massa refrigeran dan perbandingan nilai entalpi pada kondensor masuk dan keluar, semakin besar nilai laju aliran massa refrigeran ini maka 
kapasitas kalor buang kondensor juga akan meningkat, sebab kapasitas kalor buang kondensor adalah kerja yang diberikan ke kompresor dan jumlah kalor yang diserap di evaporator yang dibuang ke lingkungan.

Gambar 6 menunjukkan kapasitas penyerapan kalor di evaporator mesin pendingin tipe chiller pada pengoperasian selama 2 jam. Dari Gambar 6 dapat dilihat kapasitas penyerapan kalor rata-rata di evaporator ke cold storage $0,2831 \mathrm{~kW}$ dan kapasitas penyerapan kalor rata-rata di evaporator ke indoor $0,508 \mathrm{~kW}$

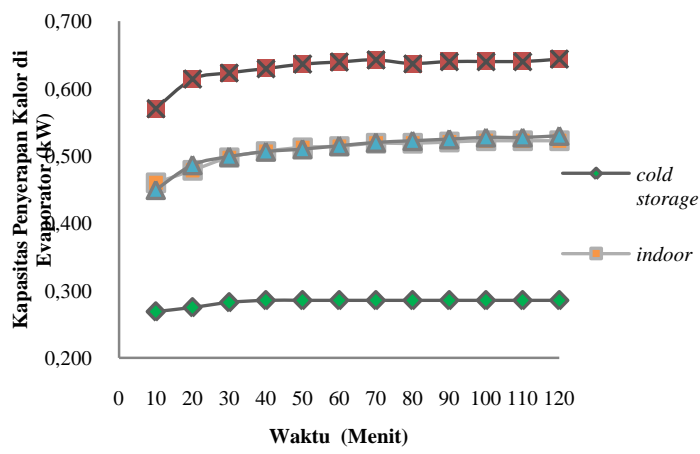

Gambar 6. Grafik perbandingan kapasitas penyerapan kalor di evaporator terhadap waktu

Kapasitas penyerapan kalor rata-rata di evaporator ke indoor dengan beban 1000 Watt adalah $0,510 \mathrm{~kW}$, dan kapasitas penyerapan kalor rata-rata di evaporator ke cold storage dan indoor secara bersamaan adalah $0,6298 \mathrm{~kW}$. Nilai tertinggi diperoleh pada pengujian ke cold storage dan indoor secara bersamaan, dan nilai terendah diperoleh pada pengujian ke cold storage. Beban yang diserap oleh ethylene glycol coolant akan didinginkan kembali oleh refrigeran pada siklus kompresi uap selama 2 jam, mengapa pada pengujian ke cold storage dan indoor nilai kapasitas baban evaporatornya lebih besar itu karena pada pengujian ini disirkulasikan secara full system, hal ini dikarenakan kapasitas beban evaporator dipengaruhi oleh laju aliran massa refrigeran dan perubahan entalpi pada evaporator, Semakin besar laju aliran massa refrigeran dan perubahan entalpi masuk dan keluar evaporator maka semakin besar pula kapasitas penyerapan kalor di evaporator, begitu juga sebaliknya.

Gambar 7 menunjukkan laju pendinginan mesin pendingin tipe chiller pada pengoperasian selama 2 jam pada pengoperasian ke cold storage, indoor, indoor beban pendingin 1000 Watt, full system (cold storage dan indoor). Dari Gambar 7 dapat dilihat laju pendinginan rata-rata ke cold storage $0,0781 \mathrm{~kJ} / \mathrm{s}$, nilai rata-rata ke indoor $0,164 \mathrm{~kJ} / \mathrm{s}$, nilai rata-rata ke indoor dengan beban 1000 Watt 0,194 kJ/s, dan nilai rata-rata ke cold storage dan indoor secara bersamaan yaitu full system cold storage $0,0489 \mathrm{~kJ} / \mathrm{s}$, full system indoor $0,1445 \mathrm{~kJ} / \mathrm{s}$. Nilai tertinggi diperoleh pada pengujian ke indoor dengan beban 1000 Watt, dan nilai terendah diperoleh pada pengujian ke full system cold storage, laju pendinginan ini sangat dipengaruhi oleh laju aliran massa ethylene glycol coolant dan perubahan temperatur. Semakin besar laju aliran massa ethylene glycol coolant dan perubahan temperatur masuk dan keluar pada cold storage dan indoor maka semakin besar pula nilai laju pendinginan pada masingmasing ruangan, sebab laju aliran massa ethylene glycol coolant yang disirkulasikan ke cold storage itu berbeda dengan yang disirkulasikan ke indoor.

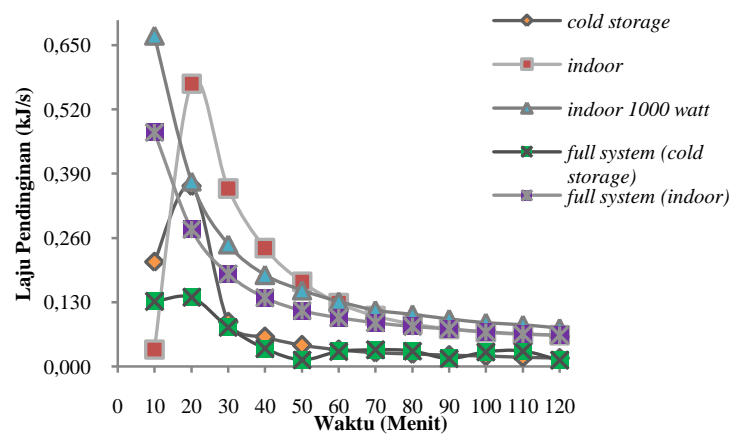

Gambar 7. Grafik Perbandingan laju pendinginan terhadap waktu

Gambar 8 menunjukkan temperatur air cold storage, temperatur indoor, temperatur indoor beban 1000Watt, dan temperatur full system (cold storage) mesin pendingin tipe chiller pada pengoperasian selama 2 jam

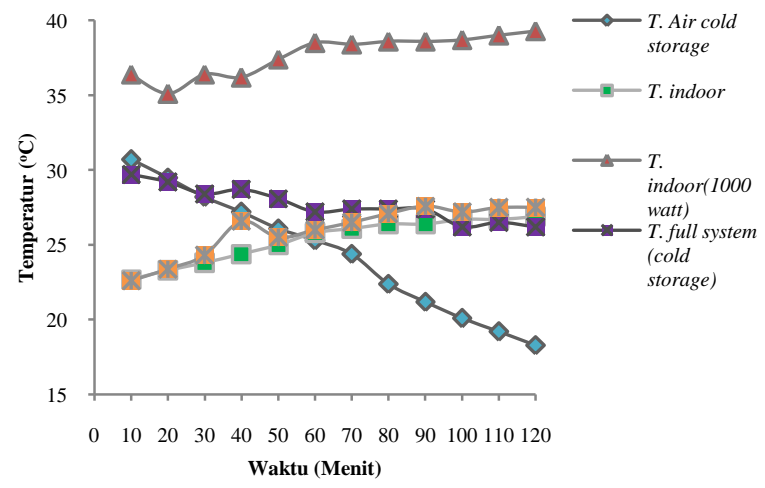

Gambar 8. Grafik perbandingan temperatur terhadap waktu

Dari Gambar 8 dapat dilihat nilai tertinggi diproleh pada pengujian yang disirkulasikan ke 
indoor dengan beban 1000 Watt, dan nilai terendah pada pengujian yang disirkulasikan ke cold storage, hal ini karena perubahan temperatur sangat dipengaruhi oleh beban yang ada pada masingmasing pengujian, baik itu di cold storage maupun di indoor. Beban saat pengujian ke cold storage adalah air, sedangkan pada indoor dilakukan dua pengujian tanpa beban dan pengujian menggunakan beban 1000 Watt. Semakin besar beban yang diberikan cold storage dan indoor maka semakin tinggi pula temperatur yang diperoleh, begitu pula sebaliknya semakin kecil beban yang diberikan pada cold storage dan indoor maka semakin rendah pula temperatur yang di peroleh.

Gambar 9 menunjukkan koefisien kinerja atau COP pada empat mode pengoperasian pada pengoperasian selama 2 jam. Dari Gambar 9 dapat dilihat nilai COP rata-rata pada pengujian yang disirkulasikan ke cold storage adalah 2,95 dan nilai rata-rata COP pada pengujian yang disirkulasikan ke indoor adalah 4,98. Sedangkan nilai rata-rata COP pada pengujian yang disirkulasikan ke indoor dengan beban 1000 Watt adalah 4,96.

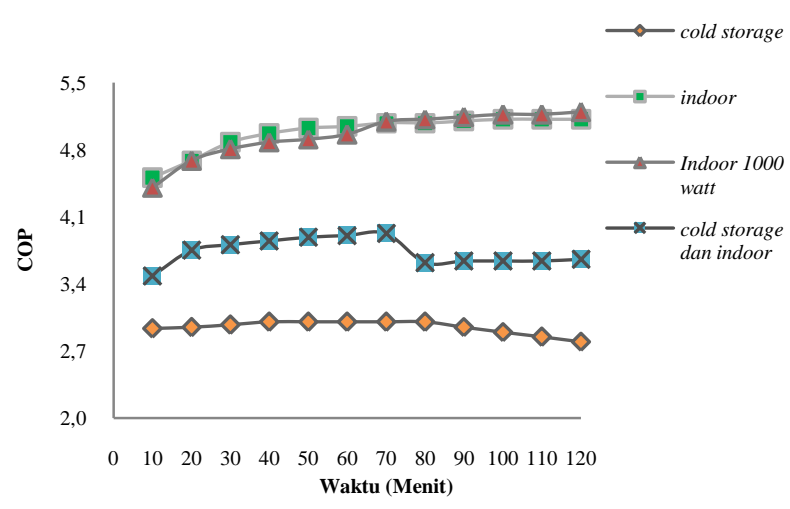

Gambar 9. Grafik perbandingan Cooficient Of Performance (COP) terhadap waktu

Nilai rata-rata COP pada pengujian yang disirkulasikan ke cold storage dan indoor secara bersamaan adalah 3,73 seperti dapat dilihat pada Gambar 9. COP adalah perbandingan antara kapasitas penyerapan kalor di evaporator terhadap kerja kompresor yang diberikan ke mesin pendingin. Semakin besar kapasitas penyerapan kalor di evaporator dan semakin kecil kerja kompresor maka nilai COP yang diperoleh akan meningkat. Nilai COP tertinggi diperoleh pada pengujian yang disirkulasikan ke indoor dengan beban 1000 Watt, hal ini karena beban yang diserap ethylene glycol coolant itu diserap kembali oleh refrigeran pada box refrigerasi, sehingga mesin refrigerasi akan bekerja lebih besar. Perbedaan nilai COP pada masingmasing pengujian itu tergantung pada mesin itu sendiri, pengujian dilakukan terhadap empat mode pengoperasian, mulai dari beban air pada cold storage, tanpa beban pendingina pada indoor dan beban pendingin 1000 Watt pada indoor, dari masing-masing pengujian ini lah yang membuat nilai COP juga berbeda.

Gambar 10 menunjukkan faktor prestasi atau PF mesin pendingin tipe chiller pada pengoperasian selama 2 jam. Dari Gambar 10 dapat dilihat nilai rata-rata faktor prestasi pada cold storage sebesar 3,93, pada indoor sebesar 4,63, pada indoor dengan beban pendingin 1000 Watt sebesar 5,97, dan pada cold storage dan indoor disirkulasikan secara bersamaan sebesar 4,75.

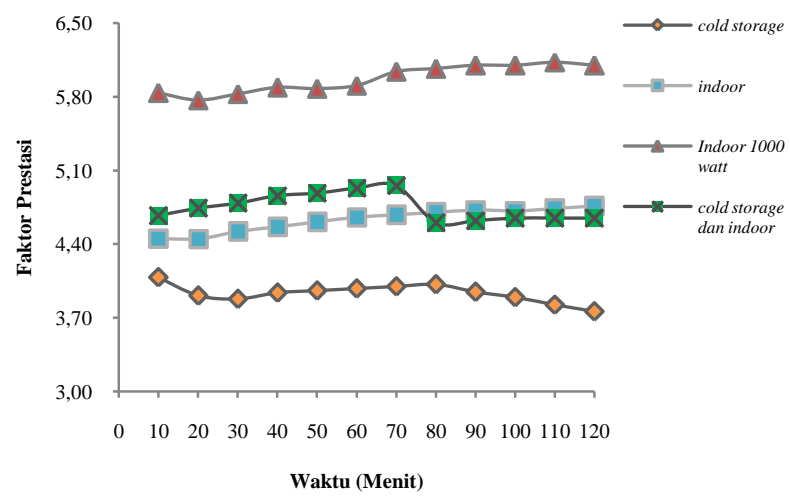

Gambar 10. Grafik perbandingan faktor prestasi (PF) terhadap waktu

Faktor prestasi tertinggi diperoleh dari pengujian yang disirkulasikan ke indoor dengan beban 1000 Watt dan nilai faktor prestasi terendah diperoleh dari pengujian yang disirkulasikan ke cold storage, ini semua disebabkan karena faktor prestasi sangat dipengaruhi oleh Kapasitas kondensor terhadap kerja kompresi, semakin besar kapasitas kondensor yang dibuang dan kerja kompresi semakin kecil maka semakin besar pula nilai faktor prestasinya, begitu juga sebaliknya, semakin kecil kapasitas kondensor yang dibuang dan kerja kompresi semakin besar maka semakin kecil pula nilai faktor prestasinya.

\section{KESIMPULAN}

Analisis performansi mesin pendingin tipe chiller untuk cold storage dan indoor menggunakan ethylene glycol coolant telah dilakukan. Hasil penelitian menunjukkan bahwa setelah ethylene glycol coolant disirkulasikan ke cold storage dan 
indoor selama 2 jam, terjadi kenaikan temperatur ethylene glycol coolant disebabkan oleh lamanya waktu dan beban. Semakin lama waktu yang dibutuhkan untuk mendinginkan cold storage dan indoor dengan beban yang besar maka akan semakin cepat pula naiknya temperatur pada ethylene glycol coolant. Pada pengujian yang disirkulasikan ke cold storage temperatur ethylene glycol coolant selama 2 jam adalah sebesar $-5,62{ }^{\circ} \mathrm{C}$, pada pengujian yang disirkulasikan ke indoor adalah sebesar $1,05{ }^{\circ} \mathrm{C}$, pengujian yang disirkulasikan ke indoor dengan beban 1000 Watt adalah sebesar $29,96{ }^{\circ} \mathrm{C}$, dan pada pengujian ke cold storage dan indoor disirkulasikan secara bersamaan adalah sebesar $24,48{ }^{\circ} \mathrm{C}$. Semakin cepat naiknya temperatur ethylene glycol coolant maka akan semakin besar pula pengaruh penyerapan kalor dari evaporator pada box refrigerasi.

Hasil pengujian yang disirkulasikan ke cold storage diperoleh nilai COP sebesar 2,80, pada pengujian yang disirkulasikan ke indoor nilai COP sebesar 5,12, pada pengujian yang disirkulasikan ke indoor dengan beban 1000 Watt nilai COP sebesar 5,19 , dan pada pengujian yang disirkulasikan ke cold storage dan indoor disirkulasikan secara bersamaan nilai COP sebesar 3,66. Performansi mesin pendingin tipe chiller di pengaruhi oleh beban, sebab beban yang semakin besar akan mempengaruhi kerja kompresor sehingga tekanan pada kompresor akan meningkat, nilai COP meningkat jika tekanan masuk pada kompresor semakin tinggi dan tekanan keluar kompresor semakin rendah, maka sebaliknya nilai COP akan semakin rendah jika tekanan masuk kompresor rendah dan tekanan keluar kompresor tinggi.

\section{DAFTAR PUSTAKA}

[1] Miller, R., Miller, Mark R., 2006, Air Conditioning and Refrigeration, McGraw-Hill, Inc., New York.

[2] http://www.travelindonesia.org/sekilas-tentangalam-indonesia/

[3] Althouse, A D., Turnquist, C H. \& Bracciano, A F., 2004, Modern Refrigeration and Air Conditioning, The Goodheart-Willcox Company, Inc. Illinois.

[4] Hanafi, Nuri., 2006, Mencari dan Memperbaiki Kerusakan Lemari Es, Edisi pertama, PT Kawan Pustaka, Jakarta.
[5] Negara, K. Metty Trisna., Wijaksana, Hendra., Suarnadwipa, Nengah. \& Sucipta, Made, 2010, "Analisa Performansi Sistem Pendingin Ruangan dan Efisiensi Energy Listrik pada Sistem Water Chiller dengan Penerapan Metode Cooled Energy Storage", Jurnal Ilmiah Teknik Mesin CakraM, Vol. 4, 43-50.

[6] Aziz, A., 2005, "Performansi Mesin Refrigerasi Kompresi Uap terhadap Massa Refrigeran Optimum Menggunakan Refrigeran Hidrokarbon", Jurnal Teknik Mesin, Vol. 2, 2933.

[7] Yudisworo, W D., Heri, J., Wibowo, H, Cooling unit performance analysis of fish (cold storage) to Improve quality in fishermencatch, Cirebon, Faculty of Engineering, UNTAG Cirebon, http://perpus.upstegal.ac.id/v4/files/e_book/artik el_84.pdf

[8] Wahyudi, E. \& Ulud, M., 2009. "Rancang bangun mesin pendingin bertemperatur dibawah $0^{\circ} \mathrm{C}$ untuk cold storage system", Tugas Akhir, Jurusan Teknik Mesin, Universitas Riau, Pekanbaru.

[9] Syahputra, H., 2015, "Kaji Eksperimental Performansi Mesin Pendingin Type Chiller untuk Cold Storage dan Indoor Menggunakan Coolant Ethylene Glikol”, Tugas Akhir, Jurusan teknik Mesin, Universitas Riau, Pekanbaru.

[10] Joseph A. 1989. Manual on Selection and Use of Engine Coolants and Cooling System Chemicals 4th Edition. American.

[11] Chandra, PT Laris., 2015, Radiator Products. http://coolant.id/tentang-prestone/_(diakses 02 April 2015).

[12] Cengel, Y A., \& Boles, M., 2008, "Thermodynamics An Engineering Approach Fifth", $6^{\text {th }}$ ed, McGraw-Hill, Inc., New York. 